Revista Iberoamericana, Vol. LXVII, Núm. 196, Julio-Setiembre 2001, 461-473

\title{
VASCO NÚÑEZ DE BALBOA Y LA GEOPSIQUIS DE UNA NACIÓN
}

\author{
POR \\ Ariadna García RodríGUez \\ New York University
}

Es un dato poco conocido el hecho de que el gran descubridor del Pacífico, Vasco Núñez de Balboa, llegara a la Tierra Firme escondido en un barril, como polizón. Más allá del nivel anecdótico, dicho "detalle menor", a veces mencionado de paso o descrito como producto del ingenio o espíritu aventurero de Balboa en los manuales de historia, es el gesto que marca el nacimiento de una nación; nacimiento éste que lleva el sello de lo subrepticio. No obstante, no es sino hasta principios de este siglo que dicho "origen" cobra su forma narrativa a partir de otro momento fundacional, no menos problemático, como lo es la tardía independencia panameña de $1903 .{ }^{1}$ A raíz de dicha independencia, la figura del conquistador se torna en uno de los símbolos de identidad nacional y el nombre de Balboa se convierte en el signo proliferado de lo auténticamente panameño: Balboa es el puerto canalero en el Pacífico, es la máxima condecoración otorgada en el país, es la estatua-monumento del héroe nacional, es el símbolo de la moneda de Panamá, es el nombre de una cerveza popular, es incluso parte de un estribillo de carnaval. Mi interés surge, entonces, a partir de este nacimiento doble, el histórico real en 1510 y la re-creación o mitificación del mismo a partir de 1903, al cual habría que agregarle una tercera fecha, que si bien no es un “origen” per se sí es el principio o comienzo de una nueva historia: Me refiero al año 2.000, fecha de entrega del canal a manos panameñas.

Con relación a lo anterior, mi investigación se enfoca en torno a la formación de un concepto de identidad nacional como forma de un discurso de "orígenes" en donde la distinción entre conquistador vs. nativo pierde su pureza para dar paso a lo que posteriormente se conoce como lo propio americano, y en el caso específico que me concierne, como lo propio panameño. Ahorabien, aunque se pueden identificar varias modalidades o narrativas en dicho discurso, dado el alcance polimórfico de este fenómeno de identidad nacional, en este artículo me ceñiré al análisis de la novela Núñez de Balboa. El tesoro del Dabaibe (1934) de Octavio Méndez Pereira, educador y político panameño, en la medida en que la

\footnotetext{
${ }^{1}$ Para una historia del descubrimiento y conquista de la Tierra Firme (Panamá) referirse a las fuentes primarias en las crónicas de Oviedo, Las Casas, Andagoya y Cieza de León. En cuanto a estudios monográficos sobre los personajes históricos ver las obras de Gasteazoro, Mena García, Jaén Suárez, Romoli, Anderson, Altolaguirre, Arciniegas. En relación al tema de la separación de Colombia ver Terán, Lemaitre Román, Morales; y para una historia panameña completa consultar los textos de Historia de M. Chong, Jaen Jr., Araúz y Pizzurno, Castillero R., entre otros.
} 
misma se convierte en la "biografía novelada” de la nación al incorporar lo geográfico como razón de ser y justificación del discurso de lo nacional. Pero antes de abordar la novela misma me gustaría contextualizar y describir, utilizando una anécdota más reciente, en qué consiste este fenómeno discursivo que yo denomino geopsiquis.

Vasco Núñez de Balboa, conquistador español del siglo XVI, adquiere la ciudadanía panameña durante los primeros años de la República, a principios de este siglo. Este "panameño nacido en España”, tal como se lo describe en 1975 durante la ceremonia de inauguración de una estatua en honor al mismo con motivo de la conmemoración del V centenario del natalicio del descubridor del Mar del Sur en su ciudad natal, Jerez de los Caballeros, España, se convierte en un “ciudadano” de las Américas gracias, no ya al hecho histórico sino, a un mito geográfico. ${ }^{2}$ El entonces embajador panameño, en el discurso que abría el acto oficial, calificó de justo homenajear la figura de Balboa ya que el Adelantado fue el productor (en el sentido de hacedor) “del tercer hecho histórico más grande del mundo, siendo el primero la venida de Jesucristo y el segundo el la venida de Cristo”; posteriormente, el diplomático finalizó agradeciendo el gesto de los jerezanos de rendirle homenaje a un “panameño nacido en Jerez de los Caballeros” (La Estrella de Panamá, 16). ${ }^{3}$

Quizás parezca redundante enfatizar algo cuya relevancia no necesita ser proclamada. No obstante, más allá de una defensa de lo obvio el fin de dicho "recordatorio" es reiterar la primacía del conquistador extremeño y por añadidura sacar a la luz el hecho geográfico, es decir poner de manifiesto la localización del evento. ${ }^{4}$ Un detalle curioso pero a la vez sintomático y relevante enmarca la anécdota que acabamos de señalar; el fragmento del discurso, en un gesto que no nos parece fortuito, parafrasea un segmento de la dedicatoria con que empieza la Historia General de las Indias de Francisco López de Gómara, en donde se coloca el descubrimiento de América en tercer lugar de importancia después de la creación del mundo y la venida de Jesucristo. En nuestra anécdota no sólo se altera el orden de prioridad(Jesucristo-América-Mar del Sur) sino que se hace hincapiéen la universalización del evento al vincularlo con lo religioso, y además se destaca en seguida el hecho de la apropiación o "nacionalización” del descubridor en el discurso oficial.

\footnotetext{
2 Para una discusión sobre la relevancia del hecho geográfico en el Istmo y el proyecto nacional consultar los ensayos de Ricaurte Soler, Cueva Perus y Castillero Calvo.

${ }^{3}$ Sacado del periódico La Estrella de Panamá del 27 de junio de 1975.

${ }^{4}$ Esta insistencia nace de la necesidad de combatir cierto "olvido" histórico que considero relevante mencionar para poder contextualizar la materia que nos atañe. Primero, el hecho de que por casi cuatro siglos la ruta sureña fuera la única vía marítima que permitía el cruce al Pacífico y viceversa contribuyó a que se recordara más la hazaña de Magallanes quien descubre el paso austral, bautiza (con el nombre de Pacífico) y cruza el mismo océano 7 años después de que Balboa, descubridor del paso terrestre del istmo. Segundo, la desaparición de todos los escritos de Balboa, junto al fracaso legal por parte de los familiares de éste por recuperar los bienes y títulos del Adelantado y la adjudicación de los mismos al gobernador enviado por la corte, Pedrarias, quien incluso ejecuta o repite una "nueva" ceremonia de posesión del Mar del Sur a la muerte del primero, ayudó en gran medida a "borrar” o distorsionar los hechos en la memoria colectiva (consultar a Romoli, Gasteazoro, Altolaguirre, etc.). Como podemos ver el Adelantado corrió con la misma suerte que Colón en más de un sentido. Es sólo a partir de finales de siglo y principios de éste que la figura de Balboa ha sido "restaurada” o recuperada por intelectuales y académicos que, queriendo restituirle a través de sus escritos la voz de la que careció por tanto tiempo, han contribuido a la mitificación del mismo.
} 
En una estrategia discursiva que recuerda el concepto derrideano de suplemento, el gesto arriba descrito conlleva una doble vertiente puesto que se añade a lo ya existente (la historia, la genealogía, etc.), reiterando la importancia del Pacífico como hecho trascendental, y en este sentido la aclaración termina siendo un exceso. Al mismo tiempo, al americanizar a la figura se substituye o suple la ausencia fundamental (es decir el lugar del evento) tornándola en el eje generador de la representación, con lo cual la aclaración crea o representa una nueva imagen que toma el lugar de la antigua figura histórica y por consiguiente no es ya exceso sino imperativo. En una misma imagen convergen los opuestos, lo propio y lo foráneo, exceso y ausencia. Y esta dualidad o hibridez americana, este continuo intercambio y/o coexistencia de contrarios, que hace de un conquistador español un panameño nacido en España, tiene un alcance que abarca todas las esferas de la cultura, desde lo literario e histórico a lo geopolítico y etnográfico, y lo popular, fenómeno que ya ha sido expresado de una manera u otra por Fernando Ortiz y Néstor García Canclini, entre otros. Es dentro de este vasto contexto en donde ubico mi estudio sobre la figura del Conquistador extremeño como el punto de enlace entre lo histórico, lo literario y lo geográfico.

Detrás del gesto de reafirmación y localización (en el sentido geográfico) de la identidad nacional, mencionado anteriormente, subyace todo un complejo sistema de apropiación y recuperación de la historia Patria cuyo fin es lograr ese "criterio de representatividad” que Angel Rama, en su libro Transculturación narrativa en América Latina, describe como "impulso modelador" de la cultura y que se gesta en Latinoamérica durante el período nacionalista de principios de siglo hasta más o menos los años $40 .^{5}$ En el caso de la novela de Méndez Pereira trato de mostrar cómo dicho criterio de representatividad justifica la construcción de una imagen de lo nacional a partir de una relectura y reescritura del "archivo” basándome en tres elementos principales: la función o rol que la figura femenina tiene como "madre” fundadora, la construcción del héroe como lo propioamericano, y la temática de lo telúrico como resorte subyacente de la obra.

En 1934, Méndez Pereira publica un libro titulado El tesoro del Dabaibe, narración de los hechos del descubrimiento del océano Pacífico en 1513, en el cual utiliza información y citas directas de las crónicas para darle al relato un tono de veracidad. ${ }^{7}$ Es por esto que Méndez Pereira abre la novela con una nota al lector en donde asegura que en su "relación no hay nada que no sea estrictamente histórico”, y según él esto no podría ser de otra forma ya que "la verdad o lo maravilloso real es más maravilloso que lo imaginario" (9, el subrayado es mío). Dos cosas sobresalen de inmediato: primero el énfasis en lo verídico del relato y segundo la descripción o clasificación del mismo como una "relación”.

Empezaré por lo segundo. En el contexto colonial el término "relación” se refería a un relato o informe de las cosas acaecidas solicitado por la corona (Mignolo 70-75). Unido a

\footnotetext{
${ }^{5}$ Estas ideas y frases en comillas provienen del primer capítulo del libro de Ángel Rama.

${ }^{6}$ El concepto de “archivo” se refiere al expuesto por Roberto González Echevarría, en su libro titulado "Myth and Archive. A Theory of Latin American Narrative”, quien lo relaciona con los conceptos de ley, poder, secreto y origen (31-32).

${ }^{7}$ Curiosamente, en 1940 el título original es cambiado a Núñez de Balboa. El tesoro del Dabaibe para la primera edición de la Espasa-Calpe y se mantiene así en las siete reimpresiones siguientes.
} 
esto, González Echevarría, en Myth and Archive, nos recuerda que la “relación” a su vez era el medio con el que el individuo contaba para establecer un lazo (textual) con el poder burocrático ya bien como reporte, confesión penal o refutación; en otras palabras, la relación era una forma de legitimización (56-57). En la novela de Méndez Pereira no se encuentra el sello distintivo de la narración en primera persona del documento legal colonial sino un narrador omnisciente en tercera persona, quien a lo largo de la obra intercala en los diálogos y descripciones información entre comillas extraída de las crónicas (Oviedo y Las Casas) para validar así su propia versión. Es necesario, entonces, suponer que el autor se siente impelido a "restaurar" y/o defender el honor del Adelantado, refutando las versiones oficiales que lo condenaron por sedición y por asesinato (contra Diego de Nicuesa). Este afán se destaca en la obra en la medida en que se presenta al héroe como una víctima de las circunstancias, aunque esto contradiga las versiones de Fernández de Oviedo y Las Casas. ${ }^{8}$

Por otra parte, el criterio de verdad al que alude el autor al inicio de la obra no se refiere a la veracidad de las crónicas sino que sugiere una nueva “verdad”, la que instituye la obra de ficción; en este sentido la obra puede leerse como un alegato a favor del Adelantado. Se acude a un modo discursivo legal predominante durante la colonia, la relación, como forma argumentativa y punto de partida de la narración, a la vez que se socaba, cuestiona y contradice la autoridad de las crónicas para narrar la historia a su modo. También según González Echevarría, una de las características más persistentes de la novela moderna es precisamente su afán en no parecer o no ser literatura, y a razón de esto adopta muchas veces formas híbridas en las que se crea "otro" texto permeado de las circunstancias socioeconómicas que lo rodean y que estará dotado con la capacidad de dar testimonio de una verdad contingente con su momento histórico (7). En este caso, las circunstancias que propician esta narración son el incipiente nacimiento de la Nación panameña a partir de su recién ganada independencia de Colombia (1903), y la íntima conexión de este hecho con la preocupante presencia norteamericana en el Istmo debido a la construcción del canal por estos.

Encuentro pertinente en este momento referirme a la idea de "nación” que Benedict Anderson desarrolla, en su libro Imagined Communities, ya que creo que la misma toca muy de cerca la problemática del caso. Según este crítico, la nación es una comunidad política imaginaria cuyos rasgos definidores son el límite (la frontera) y el Estado soberano; a su vez, Anderson también señala que la novela y la prensa sirven de medios para re-presentar dicha comunidad imaginaria nacional (6-7). En relación a la anterior definición de nación, el caso panameño difiere de la misma en tanto que la legitimidad de la nueva república se pone en duda a partir precisamente de la problemática fronteriza (Panamá, el país de las cinco fronteras como se lo ha llamado algunas veces) y de la carencia de una soberanía absoluta, elementos ambos inherentes al concepto de nación que provee Anderson. Tal situación anómala, en la que se cuestiona la validez de dicha independencia y el origen mismo de la

\footnotetext{
${ }^{8}$ Las dos cartas de Balboa fechadas el 20 de enero de 1513 y el 26 de Octubre de 1515, junto con algunos fragmentos de secretaría (del 30 de Abril, 16 de Octubre y el 27 de Noviembre de 1515) fueron tomados del libro de Altolaguirre. De Fernández de Oviedo se utilizan los Libros VIII (capítulos IV-V), IX (cap. I-IV), X (cap. Proemio-XVIII); y en Las Casas se usan el Libro II (el capítulo 62) y el Libro III (capítulos del 39 al 77).
} 
nación, hace que frente al Otro-invasor (USA) el criterio de “representatividad” buscado por la nueva república, conceptuado justamente como origen e independencia según Rama, aquí sea asumido post facto como la lucha por la soberanía en su propio territorio a manera de efecto reiterativo, y no como causa a priori, de una razón de ser que supera/trasciende lo histórico.

De allí surge la necesidad, lo cual es sintomático, de dirigirse, formar o moldear a esta «nueva» comunidad cuyo "mal más hondo es la ausencia del sentimiento de la nacionalidad en el pueblo y la falta de fe en la existencia soberana” según lo diagnostica en 1916 Eusebio A. Morales, uno de los fundadores de la República (6). Es por esto, y quizás como medida preventiva, que una de las premisas o “causas” de la separación de Panamá de Colombia se explica en términos de un llamado trascendental a cumplir con la obligación a la que estaba sujeto el Istmo dada la situación de su territorio como paso de tránsito. ${ }^{9}$ Es aquí cuando la figura del conquistador asume su papel de símbolo de lo nacional en la medida en que el mismo representa el “inicio” del país a nivel histórico-geográfico. La "relación” que la novela anuncia ser responde entonces a ese llamado de la nación que busca legitimar su existencia tornando una figura de su pasado colonial en un "foundational father", para parafrasear el título del libro de Doris Sommer Foundational Fictions, siendo ésta esa "nueva” verdad histórico-geográfica a la que me refería anteriormente.

Pero primero, para poder incorporar al Adelantado dentro de la galería de panameños ilustres era imperativa su "naturalización”. Esta forma de legitimización responde al orden de lo genealógico y lo territorial, por lo tanto, en la novela la figura histórica es asociada con lo autóctono, es decir con el paisaje y lo indígena. Lo interesante es que el puente o lazo de unión entre ambos conceptos, y por ende con el nuevo mundo, es precisamente una figura femenina cuya veracidad histórica ha sido cuestionada por muchos historiadores panameños en vista de que la misma carece de un nombre en las crónicas y de que Balboa nunca la menciona; la existencia de esta figura histórica sólo se indica en las crónicas como hija del cacique Careta que fue regalada a Balboa. ${ }^{10}$ A esta figura sin nombre se le ha bautizado como Anayansi, nombre que adopta Méndez Pereira. Por si fuera poco, las crónicas también registran la presencia de otra mujer amerindia cuyo nombre es Fulvia, según Mártir de Anglería (156), ${ }^{11}$ y cuya existencia es verificada en las distintas crónicas aunque no se la nombre. Esta otra amante india del Balboa-histórico, Fulvia, traiciona no sólo a su pueblo sino que es la causa de la tortura de su propio hermano al comunicarle a Balboa el ataque que éste y su gente planean contra él. Este detalle de intriga y traición familiar no es pasado

\footnotetext{
${ }^{9}$ Diplomático, ensayista y político nacido en Colombia, Morales, quien ocupó el cargo de ministro de gobierno en la Junta Provisional de Gobierno formada a raíz de la separación, fue el encargado de redactar el "Manifiesto" o documento dirigido a la nación y al extranjero que explicaba las razones de la independencia de Panamá de Colombia en 1903. En dicho documento se menciona como motivos de la separación del Istmo el deseo de "recobrar su soberanía" y el deber que tiene el pueblo del Istmo de desempeñar el papel a que está llamado a ejecutar dada la situación de su territorio (78).

${ }^{10}$ En cuanto a la discusión sobre la veracidad histórica de la misma ver a Castillero Calvo en Mitos y M. Chong.

${ }^{11}$ Aunque existen referencias a la existencia de esta figura amerindia en las crónicas de Las Casas y López de Gómara, pero no en Oviedo, sólo P. Mártir de Anglería cita el nombre de "Fulvia".
} 
por alto por Méndez Pereira, quien de una manera curiosa incorpora a la Fulvia-histórica (y con este mismo nombre) como personaje menor en su novela.

Las dos figuras históricas femeninas carecen de una voz propia, y al no darles un nombre (especialmente a “Anayansi”) son practicamente borradas de la historia, confundiéndolas con la nada, como dice Paz con respecto a la figura mexicana de la Malinche en las cartas de Cortés. Esto contribuye así a ese "silencio fundacional” de la conciencia americana que describe Eduardo Subirats en su libro El continente vacío. Empero, en la novela tal ausencia se convierte en uno de los ejes principales de la narración ya que a la desconocida princesa amerindia (la hija de Careta) se la representa como la figura materna fundacional de la nueva raza híbrida. Es decir, es ella el punto de contacto o comunicación entre el extranjero y la tierra. Anayansi-personaje, "reconoce o entiende” la superioridad del invasor y se ve impelida a unirse a él; ella es el vehículo por medio del cual Balboa se entera de las riquezas increíbles de un lugar llamado Dabaibe y de la existencia del Pacífico, aunque en las crónicas es otro el informante. Cabe señalar que con respecto al personaje de Anayansi en la novela, si bien en el mismo se canalizan todos los estereotipos a partir de los cuales se construye la imagen del Yo-Europeo y que hicieron posible la conquista (sumisión, sensualidad, debilidad, inferioridad, ingenuidad), se introduce una variante al caracterizarla como una "seductora Salomé” que hechiza a Balboa, planteando con esto una colonización a la inversa dada en términos de lo erótico. Nos encontramos con una "femme fatale" que es capaz de encantar por medio de un sensual baile, llamado por el autor "La danza del amor" (42). Dicha escena, descrita a la manera del modernismo exoticista latinoamericano decimonónico y que merece ocupar todo un capítulo de la novela, plantea la "conquista” del "Otro" extranjero.

Las discrepancias y similitudes entre las crónicas y la novela, es decir lo que se dice y lo que se oculta, son reveladoras. En la novela se sugiere que las acciones del conquistador llevan el sello del amor especial que por la amerindia sentía el español, aunque en realidad las Anayansis de Balboa hayan sido muchas como apuntan las crónicas. Además, se presenta en la obra de ficción una escena de seducción a través de la danza, cosa que no existe en las crónicas. Y posteriormente, se identifica a Anayansi-personaje como la motivación o razón de la decapitación del héroe. Esto se explica en términos de un triángulo amoroso en el que los celos que uno de los soldados de Balboa (Garabito) sentía, debido a su interés por la hija de Careta, lo llevan a traicionar al Adelantado revelándole información a Pedrarias. Si bien es cierto que en Las Casas se mencionan las tensiones entre Balboa y este soldado, este factor no deja de ser presentado como un elemento menor dentro de toda la intriga de la que Balboa es víctima.

El problema surge cuando es necesario disculpar o atenuar en la novela el gesto fratricida de la Fulvia-histórica antes mencionada; es decir, cómo representar la traición que permitirá la formación de otra raza. Para esto se recurre a la Anayansi-ficticia como la portavoz del mensaje y no a la primera (Fulvia-personaje). En otras palabras, la Fulviaficticia le confiesa a Anayansi-personaje lo que trama su hermano y es ésta última la que le revela todo al conquistador. Con esto, técnicamente, en la novela no es la hermana la traidora sino un tercero (Anayansi-ficticia) cuya motivación es el amor. Este intercambio en los roles en contraste con la versión histórica real es contradictorio, ya que si bien se pretende disculpar o disimular la traición fratricida como el origen de la nación, esto se cancela en 
el momento en que la Anayansi-personaje se refiere a la Fulvia-ficticia como "nuestra esclava” (56). Esta Salomé o "Venus de cobre”, como la describe el autor en la novela (39) - causante de la decapitación simbólica de un pueblo — de conquistada pasa a ser conquistadora y aliada. Y aunque para salvaguardar la pureza de la unión entre el colonizador y la amerindia se solapa la promiscuidad del español al hacer de la segunda concubina una esclava, se sigue manteniendo el paradigma de subyugación a través de un proceso de asimilación.

Esta integración a la cultura del Otro — por parte de Anayansi— se explica en la novela sobre la base de un providencialismo cuyo comportamiento del personaje responde al llamado superior de la formación de una nueva raza. Aunque mucho más se podría añadir en este punto, me restrinjo a señalar dos cosas: primero, que con la imagen de Anayansi como “conquistadora” en la novela se reinscribe la relación jerárquica de poder colonial (amo/ esclavo) desde el interior, en la medida en que se despoja al ente real de su propia memoria histórica y se le impone una identidad desde el exterior; proceso descrito por Subirats como un vaciamiento de la conciencia americana. Y en segundo lugar, es que ¿no está acaso la misma traición fratricida contenida en la separación de Panamá de Colombia a los ojos del resto de Latinoamérica en ese momento? ¿No es acaso el llamado de Anayansi-personaje una alusión al deber trascendental del Istmo dada su situación geográfica?. Como resultado directo del gesto anterior, la desconocida no sólo adquiere un nombre, “Anayansi”, sino que además se convierte en un elemento crucial del discurso panameño de identidad nacional.

Por una parte, quizás la mejor prueba de la relevancia de esta figura amerindia en el proyecto de contrucción de la nación es el hecho de que si bien Anayansi-personaje es una invención literaria, no es, como se cree, una invención de Méndez Pereira sino el producto de conversaciones y tertulias de intelectuales en un café a principios de los años veinte. Dicho grupo de letrados, movidos por un interés colectivo por proveer a Balboa de una pareja, le dan vida y nombre a la desconocida; tal vez con el afán de crear así el romance nacional apropiado. Tal hecho explicaría entonces por qué el personaje de Anayansi aparece, como compañera del Adelantado y con dicho nombre, por primera vez en un libro de 1926 titulado Caciques y conquistadores del nicaragüense Salvador Calderón Ramírez. Dicho escritor no sólo vivió y participó de la vida intelectual en Panamá sino que también fue amigo de Méndez Pereira. Además, Calderón Ramírez fue catalogado, por el presidente del país de aquel entonces, como el "Ricardo Palma panameño" en vista de la naturaleza de su libro cuyo formato es el de las "tradiciones”; un género literario que hasta ese momento hacía falta en un canon que estaba en el proceso de construirse. ${ }^{12}$

Por otra parte, tenemos que Méndez Pereira, a través de un proceso que llamo

\footnotetext{
${ }^{12}$ Hasta ahora no me ha sido posible esclarecer el origen y/o sentido del nombre Anayansi aunque he encontrado dos datos que, si bien pueden ser cuestionables, no dejan de ser interesantes como posibles hipótesis sobre la procedencia de dicho nombre. Mi primer dato proviene de la tesis o trabajo de graduación de Matilde Edwards que trata sobre esta misma novela de Méndez Pereira. En dicho trabajo, la autora establece que "Anayansi” parece el resultado de una mezcla del castellano "Ana” con terminación indígena "Yansi”, opinión ésta que coincide con mi propia hipótesis inicial sobre el significado del nombre. No obstante, según la autora de esta tesis Méndez Pereira le confiesa que el nombre lo leyó en una vieja crónica de difícil acceso o localización (184), pero en vista de que el
} 
“naturalización”, no sólo establece la conexión del héroe con la tierra por medio de la figura de la indígena (en la medida en que a mayor amor mayor apego e interés por cultivar la región) sino que además presenta al conquistador, Balboa, como un profeta de su pueblo. Esto se manifiesta en la novela en dos momentos cruciales: a la hora de la muerte, Balboapersonaje ve el futuro del Istmo, ve la tierra dividida en dos y poblada de extraña gente "fornid[a] y rubi[a]" (135-137); y una vez muerto, al aparecérsele como fantasma a Anayansi le señala a ésta la ruta transatlántica a seguir, del Atlántico al Pacífico. La referencia histórica aquí no es otra que la implícita construcción del canal por los americanos. Esta premonición o visión del canal transforma a la figura histórica en profeta de su tierra y lo convierte así en emblema por excelencia de lo nacional, ya que junto con la construcción del canal se inicia el proceso de monumentalización de la historia. Sin embargo, ¿no se trata una vez más de una identidad impuesta desde el exterior, como en el caso de Anayansi, pero ahora curiosamente aplicada al conquistador mismo?. Es decir, en el momento desde el cual se escribe la novela, lo foráneo es el rubio americano y no ya el rubio español (Balboa mismo). El conquistador al final de la obra ha sido asimiliado o transformado en lo propio o lo nacional por oposición a todo lo que el nuevo conquistador americano representa.

La narración, como hemos visto, re-inscribe o re-escribe el pasado incorporando el motivo geográfico de la agenda política de autolegitimación y discurso de lo nacional de ese

nombre de la crónica no se menciona la referencia adquiere un cáracter informal que da pie a especular sobre la veracidad de la información provista. Es decir, no podemos saber con exactitud si es la negligencia de Edwards o un olvido (intencional o no) o reserva de parte del escritor lo que nos priva de la fuente bibliográfica. La otra pista sobre el asunto, versión por la cual me inclino ya que un origen colectivo del nombre explicaría el silencio u olvido de Méndez Pereira, me fue provista en una entrevista personal hecha al profesor Marcos A. Robles, historiador y jefe de la sección de libros raros y antiguos de la biblioteca de la Universidad de Panamá. Según este historiador, es probable que dicho nombre tuviera un origen colectivo producto de alguna tertulia o conversación informal en el Café Coca Cola, lugar donde se reunían los intelectuales de la época durante los primeros años de la República. En dichas reuniones salió a relucir la aparente soledad amorosa de Balboa, en comparación con otras figuras españolas como Cortés, y en respuesta a esa preocupación se formalizó la idea de acompañar a Balboa de una dama y de escribir sobre ella. A grosso modo, éste es el resumen de lo que parece ser un secreto a voces en los círculos académicos panameños pero de lo cual no hay ninguna documentación o registro oficial que lo corrobore. Lo que sí es incuestionable es la participación de Méndez Pereira no sólo en dichas tertulias sino en todo el ámbito intelectual de su época; se puede asumir entonces que Calderón R., siendo residente de Panamá por este mismo período y amigo de Méndez Pereira, también haya participado de dicho medio. Aunque no podría determinarse si hubo un acuerdo entre ambos escritores con respecto al nombre de la amerindia, lo cierto es que dicho nombre aparece por primera vez en 1926 en el libro del nicaragüense, cuya obra está hecha siguiendo el modelo de las Tradiciones peruanas y en donde se narran hazañas y anécdotas de indios y conquistadores de la Tierra Firme (Panamá) y Nicaragua. Debido a este detalle, como ya mencioné anteriormente, se le adjudica a este escritor el título del "Ricardo Palma panameño" — según una carta del presidente de Panamá de ese momento, Ricardo J. Alfaro, dirigida al autor con motivo de la publicación de la obra. Tanto dicha carta del presidente como otra carta de Méndez Pereira para Calderón R. se incluyen a manera de prólogo en la obra. El detalle del nombre, o mejor dicho de las historias del misterio de su origen, lo cual trae a la memoria los cuentos de Borges, no debe pasar desapercibido en vista de la relevancia que cobra la figura de "Anayansi" dentro del discurso de identidad nacional que Méndez Pereira trata de fomentar. 
momento. Para la nueva República, dicho evento — el canal— se convierte en un elemento crucial en el desarrollo de la noción de ciudadanía: la región — el istmo— había finalmente logrado realizar su destino como vía de tránsito que conectaba los dos océanos para el beneficio del mundo. Luego entonces, Méndez Pereira (que en algunos de sus escritos políticos había expresado ya la necesidad de educar y crear en el pueblo una consciencia nacional), usa la figura del Balboa-personaje como emblema de la herencia hispana en contra de la inminente amenaza del norte y así hace de Balboa el símbolo del ideal nacional que se necesitaba.

Lo curioso de este hispanismo de Méndez Pereira es que no coincide del todo con el tono nostálgico del hispanismo puertorriqueño de principios de siglo; ni tampoco se plantea en términos del ideal arielista que opone a la barbarie materialista de la América anglosajona, una América Latina, aristócrata y heredera de la cultura clásica grecorromana. Méndez Pereira se sitúa más bien en un ambivalente plano intermedio, y propone un héroe nacional que apela tanto a la tradición y herencia del pasado hispano como también a ciertos valores o categorías pragmáticas que se acercan más al modelo nórdico. Esta ambigüedad en la definición de la nueva nación es lo que le permite a esta comunidad imaginaria panameña, para usar los términos de Anderson, visualizarse de una manera abarcadora y global, a pesar o precisamente a causa de su problema fronterizo y de ser un estado soberano a medias, incorporando como ciudadanos suyos desde ex-nacionales colombianos hasta antiguos conquistadores españoles. El mecanismo por medio del cual se logra dicha "naturalización" de la figura histórica se puede apreciar más claramente en un ensayo político de Méndez Pereira de 1923, titulado “Concepto de ciudadanía”, en donde él plantea que la noción de ciudadanía se define sobre la base de una categoría atemporal y ubicua que no es otra que el trabajo (En el surco, 13). En otras palabras, la idea de ciudadanía para el caso panameño no está limitada ya a tener una tierra natal designada por nacimiento o por ser un antiguo colono de la misma, como en Europa, sino que incorpora el concepto de trabajo como una virtud que puede incluir a los nuevos colonos como candidatos a tal ciudadanía. Quien trabaje la tierra o haga algo productivo de ella (como es el caso de Balboa-personaje) puede convertirse en ciudadano de dicha nación. En la misma medida en que los panameños de principio de siglo se veían a sí mismos como “constructores” de una "nueva” nación (acto que les permitía ganarse su ciudadanía), el conquistador español del siglo XVI que logró organizar y construir una comunidad en medio de la selva, según las crónicas, también puede ser percibido como otro ciudadano.

La yuxtaposición, contraposición o coexistencia entre tradición o costumbre vs. productividad social o — para usar los términos actuales relacionados con el canal— entre soberanía vs. servicio da cabida a un discurso de "orígenes" cuya ambivalencia hace imposible la definición e incluso la "localización” de la identidad panameña. Tomando en consideración lo anterior es indicativo, entonces, el uso de frases tales como "Panamá y/o el Caribe, Centroamérica y/o Panamá” en títulos de periódicos, revistas o libros, en las que las conjunciones "Y”/“O” son deícticos que introducen, simultáneamente y por partida doble, a nivel lingüístico tanto la negación como la reiteración de la problemática de la ausencia/presencia o exclusión/inclusión de este fenómeno discursivo que denomino geopsiquis. Y cuando de literatura se trata, este mismo fenómeno de identidad nacional un tanto híbrida se manifiesta a través de una polémica sobre el origen de la "presencia de una 
sostenible faena literaria” (Jurado, 31-32) en el Istmo. En la medida en que se cuestionan tanto el cuándo y el cómo de la literatura nacional se pueden encontrar versiones que abogan por un origen reciente del quehacer literario de la nueva república, o por un origen cuyas raíces datan desde la colonia. Por ejemplo, hay quienes plantean que Panamá ha tenido una tradición narrativa que empezó en el siglo XIX con la publicación de La verdad triunfante, de Gil Colunje, una novela rómantica de 1849, mientras que otros insisten en que tal tradición no existe sino hasta el siglo XX. ${ }^{13}$ Por otro lado, para algunos críticos, como Ramón H. Jurado, durante las primeras décadas de la República el motivo telúrico es reemplazado por una fe en el determinismo geográfico del Istmo (43),${ }^{14}$ representado por historias como la de Méndez Pereira, en tanto que para otros por el contrario tal determinismo es el principio mismo de la literatura panameña, un principio que se puede rastrear hasta la colonia.

Quizás toda esta polémica explique un poco el por qué es tan difícil “localizar” o situar a la literatura panameña en los manuales y antologías literarias tanto de la región como del continente. En la mayoría de los casos dicha sección sobre la literatura de Panamá brilla por su ausencia o es muy escasa. Esto se debe a que acaso se le considera una literatura "menor" en relación al resto de la literatura latinoamericana, o bien porque a nivel conceptual el poder ubicar o imaginar la problemática de lo propio panameño dentro de un contexto ya sea caribeño, centroamericano o colombiano representa un ejercicio mental de una validez cuestionable; tal como lo sería cualquier taxonomía, clasificación, nomenclatura u organización arbitrariamente impuesta, y cuyo carácter dice más de nuestras propias limitaciones y necesidades como humanos que de la cosa en sí.

\footnotetext{
${ }^{13}$ La novela de Gil Colunje fue una novela por entregas (1849) luego hecha folletín en 1901. En 1948, Rodrigo Miró, el más importante antologista e historiador literario panameño, identifica como "primer ensayo" de novela la obra de Colunje mientras señala como "punto de partida" de la novela en el Istmo, la novela Josefina (1903) de Julio Ardila. A partitr de entonces, las opiniones y/o criterios sobre cuándo o cómo empieza la tradición narrativa panameña divergen y se contradicen; al respecto, se puede consultar las obras de Revilla, E. Ramírez, García S., Miró, Jurado, Vergara Díaz.

14 Jurado, quien no cuestiona la existencia de un pasado literario colonial panameño pero el cual encuentra tan limitado o incipiente como el de otras literaturas nacionales americanas, plantea la problemática de la novelística panameña con base en una dicotomía entre universalismo/localismo (o "ruralismo" en palabras suyas). Partiendo de la premisa de la "presencia de una sostenible faena literaria” en el Istmo (31-32), este crítico hace un análisis descriptivo de los factores socio-históricos determinantes en el proceso de formación de la "novela de la República" durante los primeros 40 años de vida independiente de la nación. Dentro de su esquema, la obra de Méndez Pereira encaja en el período titulado "presentimiento y duda", momento en el que la "ilusión” del Canal como solución a los problemas de la nación empieza a tambalearse (43-49). Lo interesente de este ensayo es que establece que la temática canalera de esos primeros años se caracteriza por la ausencia de un sentimiento nacional verdadero en el imaginario político del Estado y el pueblo. Un ausentismo que él tilda ya bien de escapista o de universalismo mal entendido, cuya contraparte aparece o cobra "voz propia” a partir de una vuelta a lo auténticamente nacional: el campo o lo rural (46-60). Los postulados de dicho fenómeno literario, que Jurado denomina como "ruralismo" y que empieza a finales de los años 30 según este autor, contradicen las premisas de un proyecto de identidad nacional de base canalero-citadina y con aspiraciones cosmopolitas como lo era el representado por Méndez Pereira y su obra.
} 
BiBliografíA

Altolaguirre y Duvale, Ángel (de). Vasco Núñez de Balboa. Madrid: Imprenta del patronato de huérfanos de Intendencia e intervención militares, 1914.

Andagoya, Pascual de. Relación y documentos. Adrián Blázquez, ed. Crónicas de América. Madrid: Historia 16, 1986.

Anderson, Benedict. Imagined Communities: Reflections on the Origin and Spread of Nationalism. Londres: Verso, 1991.

Anderson, Charles L. G. Vasco Núñez de Balboa. Westport: Greenwood,1970.

Anglería, Pedro Mártir de. Décadas del Nuevo Mundo. Joaquín Torres Asensio, trad. Buenos Aires: Editorial Bajel, 1944.

Araúz, Celestino Andrés y Patricia Pizzurno Gelós. El Panamá colombiano (1821-1903). Panamá: Primer Banco de Ahorros \& Diario La Prensa, 1993.

El Panamá hispano (1501-1821). 3a ed. Panamá: Diario La Prensa, 1997.

Estudios sobre el Panamá republicano (1903-1989). Panamá: Manfer, S.A., 1996.

Arciniegas, Germán. Biografía del Caribe. 2a ed. Sepan Cuantos \#406. México: Editorial Porrúa, S.A., 1993.

Castillero Calvo, Alfredo. “Quinto Centenario: Celebración o repudio e identidad nacional. Análisis de una polémica”. Revista Nacional de Cultura. Nueva época 25 (1992): 1732.

Mitos, realidades y conciencia histórica: Nuevos retos del historiador panameño. Acto de fundación del Colegio panameño de historiadores. Panamá: n. p.,1996.

Castillero R., Ernesto J. Lecciones de Historia Patria. Panamá: Cultural Panameña, 1967. Cieza de León, Pedro. La crónica del Perú. Madrid: Espasa-Calpe, 1932.

Cueva Perus, Marcos. Sistema productivo, territorio y nación en América Latina: El caso de Panamá. Instituto de Investigaciones Sociales. México: UNAM, 1997.

Chong, Moisés. Historia de Panamá. 3a ed. Panamá: Ediciones Guadalupe, Ltda, 1975.

Derrida, Jacques. Of Grammatology. Baltimore y Londres: The Johns Hopkins University Press, 1976.

Edwards I., Matilde. “El tesoro del Dabaibe de Méndez Pereira”. Tesis. Universidad de Panamá, 1957.

Fernández de Oviedo y Valdés, Gonzalo. Historia general y natural de las Indias (1535 y 1855). Tomo 119. Juan Pérez de Tudela Bueso, ed. Madrid: BAE, 1959.

García Canclini, Néstor. Culturas Híbridas: Estrategias para entrary salir de la Modernidad. México: Editorial Grijalbo, S. A., 1990.

García S., Ismael. Historia de la literatura panameña. Panamá: Manfer, S.A., 1986.

Gasteazoro, Carlos M. “Balboa, Pedrarias y Oviedo”. Revista Nacional de Cultura. Nueva Época \# 23 (1991): 47-53.

“El ciclo de Pedrarias: Las grandes conquistas”. Revista Nacional de Cultura. Nueva Época \# 23 (1991): 103-117.

Introducción al Estudio de la Historia de Panamá: Fuentes de la Época Hispánica. 2a. edición. Panamá: Editores Manfer, S.A., 1990.

Gómara, Francisco López de. Historia General de las Indias y Conquista de México. [1552] Edición facsímil. Barcelona: Amigos del Círculo del Bibliófilo, 1982. 
González Echevarría, Roberto. Myth and Archive: A Theory of Latin American Narrative. Cambridge: Cambridge University Press, 1990.

Jaén Jr, Ricardo. Brevario de Historia Patria. Panamá: Duplicadora Industrial, S.A., 1967. Jaén Suárez, Omar. "Balboa, héroe universal panameño". Revista Nacional de Cultura. Nueva época 25 (1992): 95-100.

Jurado, Ramón H. Itinerario y rumbo de la novela panameña. Panamá: Editorial Cultural Panameña, 1978.

Las Casas, Bartolomé de. Historia de las Indias (1821). Tres tomos. André Saint-Lu, ed. Caracas: Ayacucho, 1986.

Lemaitre Román, Eduardo. Panamá y su separación de Colombia. Una historia que parece novela. 2a ed. Bogotá: Italgraf, S,A., 1972.

Mena García, Carmen. Pedrarias Davila. Colección de Bolsillo \# 124. Sevilla: Servicio de Publicaciones de la Universidad de Sevilla, 1992.

Méndez Pereira, Octavio. En el surco. Discursos compilados con permiso del autor por la casa editorial Minerva y pronunciados por áquel como secretario de instrucción publica durante el año escolar 1923-1924. Panamá: Editorial Minerva.

Núñez de Balboa. El tesoro de Dabaibe (1934). Colección Austral \# 166. Sexta Edición. Madrid: Espasa-Calpe, S.A., 1972.

Miró, Rodrigo. La literatura Panameña (Origen y Proceso).8a ed. Panamá: EUPAN, 1996.

Mignolo, Walter. "Cartas, crónicas y relaciones del decubrimiento y la conquista”. Historia de la literatura hispanoamericana. Epoca Colonial. Luis Iñigo Madrigal, coord. Madrid: Cátedra, 1982. 57-116.

“Monumento de Balboa en Jerez de los Caballeros”. La estrella de Panamá (27 de junio de 1975): $16+$.

Morales, Eusebio A. “Manifiesto”. Iniciación literaria. 18a ed. Libro segundo. Miguel Mejía Dutary, comp. Panamá: Editoria Istmeña, 1982. 6-8.

Paz, Octavio. El laberinto de la soledad. Colección Popular. México: Fondo de Cultura Económica, 1959.

Rama, Ángel. Transculturación narrativa en América Latina. México: Siglo xxı Editores, 1982.

Ramírez, Emilia R. de, Gladys B. de Ayala y Susana R. de Torrijos. Panorama de las Literaturas Hispanoamericana y Panameña. XVIII edición. Panamá: Ministerio de Educación, 1984.

Ramírez, Salvador Calderón. Caciques y conquistadores. Panamá: Imprenta Nacional, 1926.

Revilla Argüeso, Angel. Cultura Hispanoamericana en el Istmo de Panamá. ECU Ediciones. San José: Litografía e Imprenta LIL, S.A., 1987.

Robles, Marcos A. Entrevista personal. 3 de junio de 1998.

Romoli, Kathleen. Vasco Núñez de Balboa, descubridor del Pacífico. Felipe Ximénez de Sandoval, trad. Madrid: Espasa-Calpe, 1955.

Soler, Ricaurte. Formas ideológicas de la nación panameña. 5ta edición. San José: Editorial Universitaria Centroamericana, EDUCA, 1977.

Panamá en el Mundo Américano. Panamá: Cultural Panameña, 1971. 
Pensamiento Panameño y Concepción de la Nacionalidad durante el Siglo XIX (Para la historia de las ideas en el Istmo). 2a edición. Prólogo de Rodrigo Miró. Panamá: Editores Librería Cultural Panameña, 1971.

Sommer, Doris. Foundational Fictions: The National Romances of Latin America. Berkeley: University of California Press, 1991.

Subirats, Eduardo. El continente vacío. La conquista del Nuevo Mundo y la conciencia moderna. Madrid: Anaya \& Mario Muchnik, 1994. América o la memoria histórica. Caracas: Monte Ávila Editores, 1994.

Terán, Oscar. Del tratado Herrán-Hay al tratado Hay-Bunau Varilla. Panamá. Historia crítica del atraco yanqui mal llamado en Colombia "La Pérdida de Panamá” y en Panamá “Nuestra Independencia de Colombia”. Bogotá: Carlos Valencia Editores, Ltda., 1976.

Vergara Díaz, Humberto. 70 autores de Latinoamérica: balance histórico de la literatura hispanoamericana y panameña. Panamá: Manfer Ediciones, S. A., 1982. 